\title{
Effect of ambient temperature on incidence of tuberculosis and effect modification by meteorological factors in Jinan, China during 2012- 2015
}

\author{
Runze Ye \\ Shandong University \\ Liangliang Cui \\ Jinan Municipal Center for Disease Control and Prevention \\ Jingwen Zhou \\ Jinan Municipal Center for Disease Control and Prevention \\ Meihua Wang \\ Jinan Municipal Center for Disease Control and Prevention \\ Chongqi Jia ( $\nabla_{\text {jiachongqi@sdu.edu.cn ) }}$ \\ https://orcid.org/0000-0002-7239-5641 \\ Shiman Ruan \\ Jinan Municipal Center for Disease Control and Prevention
}

\section{Research}

Keywords: Ambient temperature; tuberculosis; effect modification; distributed lag non-linear model

Posted Date: February 20th, 2020

DOI: https://doi.org/10.21203/rs.2.24032/v1

License: (a) (i) This work is licensed under a Creative Commons Attribution 4.0 International License.

Read Full License 


\section{Abstract}

\section{Objective}

For assessing the nonlinearity and delayed effect of temperature on incidence of Tuberculosis (TB) and effect modification by meteorology factors, daily data on meteorological factors, air pollutants and incidence were obtained in Jinan, China, from 2012 to 2015.

\section{Methods}

A distributed lag non-linear model (DLNM) combined with quasi-Poisson regression model was employed to assess the nonlinearity and the delayed effect of associations. We further built a series of weatherstratified models categorizing the meteorology factors into two levels to assess the effect modification of the ambient temperature effect.

\section{Results}

The correlation between tuberculosis (TB) cases and daily average temperature ( $\left.T_{\text {mean }}\right)$ was nonlinear with a delayed effect. At the current day (lag 0 ), the increase of $T_{\text {mean }}$ decreased the risk of TB incidence; over lag 0-70 days, the decrease of low $T_{\text {mean }}$ and the increase of the high $T_{\text {mean }}$ both indicated the increased risk of TB. The cold temperature showed an immediate effect at the current day, with a harvesting effect in the following days. There was no significant harvesting effect in hot effect. Meanwhile, the effect of hot temperature on TB appeared with an about two-week lag and was lower than cold effect. The effect modifications by relative humidity, wind speed and sunshine duration were observed.

\section{Conclusion}

Results indicate that there was a nonlinear correlation with a harvesting effect between temperature and TB in Jinan, and both cold effect and heat effect exist the delayed effect. Results also pointed to the importance of considering effect modification by meteorological factors in assessing temperature effects on incidence of TB. Which might shed light on the strategy of TB prevention and control.

\section{Introduction}

In the past decades, the prospect of continued global warming, climate change, serious pollution and extreme weather events has concentrated attention on the harmful impacts of environment on public health. Many studies [1-3] have reported an increased mortality caused by high or low temperature. However, previous studies mainly focused on the relationships between meteorological factors and chronic diseases, such as respiratory diseases (RD) [4], cardiovascular diseases (CVD) and myocardial infarction [5]. With growing concerns about climate change, an increasing number of studies also began to focus on associations of weather variability with the fluctuations of infectious diseases and suggested 
that weather factors play an important role in infection incidences [6], such as hand-foot-mouth disease [7], Zika virus infection [8] and diarrhea [9].

Worldwide, Tuberculosis (TB) is one of the top 10 causes of death and the leading cause from a single infectious agent (above HIV/AIDS). Millions of people continue to fall sick with TB each year. Two thirds of cases were in eight countries with the highest rates in India (27\%), China (9\%) and Indonesia (8\%). China is not only the second largest country with the highest number of cases, but also one of the three countries with the largest numbers of multidrug-resistant and rifampicin-resistance (MDR/RR-TB) (13\%). [10] TB remains an ongoing intractable health challenge in China.

TB spread pattern is influenced by geographic and social factors, which indicated it is necessary to assess the impacts of temperature on TB in various regions. Seasonal fluctuations in TB notifications have been reported from a number of researches [11-13], these studies also suggest delayed effects of environmental factors. Further, it has been shown that the risk of TB has a correlation with climate and extreme heat or cold temperatures. $[14,15]$ Due to the diversity of temperature ranges and fluctuations, climate types, and economic environments in different regions, the relationships between temperature and TB in different regions should be studied and will provide important evidence also for other countries.

Moreover, a lot of studies in different regions put forward that other environmental factors can also exert an effect on TB incidence. For example, the areas with extra dry climate are high-risk regions of TB [14]; the decrease of SD lead to an increased risk of TB [16]; the TB incidence are positively associated with the WS $[17,18]$. The meteorological and environmental factors are some of the central variables affecting the airborne transmission of pathogens. $[19,20]$ Yet there have been only limited studies on effect modification by other meteorological factors on temperature effect on TB.

In addition to meteorological factors, air pollution has also been linked to TB risk. The effects of carbon monoxide (CO) and particulate matter less than $2.5 \mu \mathrm{m}$ in aerodynamic diameter $\left(\mathrm{PM}_{2.5}\right)$ on incidence of TB were significant. [21-23] In South Korea, the exposure to high concentrations of suspended particles increased at 1.27 times the incidence of TB [24]. However, many studies [4, 14] of ambient temperature and health outcome did not account for air pollutants, and in the previous review [25], it was not clear from the few studies conducted whether air pollutants acted as confounders, effect modifiers, or both. It is critical to control the effect of pollutants in models with ambient temperature, since they may often exert the influence on a daily basis [26]. On the other hand, Jinan is a typical heavily polluted area, and the relationship between cases of TB and pollutants have been determined in Jinan. Thus, the actual association between ambient temperature and incidence can be observed, only after controlling pollutants in the models.

Here, this study aimed to assess the effect of ambient temperature as well as delayed effect on TB based on the infectious disease surveillance data in Jinan by using distributed lag non-linear model (DLNM) controlling the effects of the pollutants affecting the infection of TB. Although almost all studies that examine the effects of air pollution and mortality have controlled for meteorological factors, control for 
air pollution in studies assessing the effects of temperature has been rare. Simultaneously, based on the relationship between $T_{\text {mean }}$ and incidence of TB, this study also investigated if the other meteorological factors modify the temperature-TB incidence relationship. It will help plan effective intervention strategies for the prevention and control of TB in similar populations and help public health professionals to make response.

\section{Materials And Methods}

\subsection{Study area and population}

Jinan is located in the Mideast of China $\left(36^{\circ} 01^{\prime} \mathrm{N}\right.$ to $37^{\circ} 32^{\prime} \mathrm{N}, 116^{\circ} 11^{\prime} \mathrm{E}$ to $\left.117^{\circ} 44^{\prime} \mathrm{E}\right)$. It towards the south is Tai Mountain, whilst the north is bordered by the Yellow River. Belonged to the warm temperate continental climate, four seasons. It is dry and rainless in spring, hot and rainy in summer, cool and sunny in the fall, freezing and dry in winter. As the capital city of Shandong province, Jinan is the center of politics, economies and communication in the province. The total area is $7,998 \mathrm{~km}^{2}$, and the total population reaches 7.32 million. The male/female ratio of target population is 0.984 . Fourteen percent of the total population is the elderly ( $\geq 65$ years of age). In 2017 , the density of population is 805 person $/ \mathrm{km}^{2}$.[27] In recent years, Jinan's annual average temperature has gradually increased and extreme weather events have occurred frequently with extreme $T_{\max }$ recorded $41.7^{\circ} \mathrm{C}$ and extreme $T_{\min }$ recorded $-17{ }^{\circ} \mathrm{C}$ [28]. In 2017, the number of high temperature (daily maximum temperature $\geq 35^{\circ} \mathrm{C}$ ) days reached 30, which was the most numerous days for nearly two decades.[29] At the same time, Jinan is a typical high-pollution city. At the beginning and end of each year, continuous haze appears in Jinan.[29, 30]

\subsection{Data collection}

Daily TB cases counts data, from January 1, 2012 to December 31, 2015, were obtained from Jinan Municipal Center for Disease Control and Prevention (JMCDC), which has access to the China National Notifiable Disease Surveillance System. As a notifiable infectious disease in China, all cases of TB are required to be reported online within 24 hours after diagnosis in the hospital. The TB cases in the JMCDC database included all newly diagnosed active pulmonary TB cases.

Daily meteorological data including daily maximum $\left(T_{\max }\right)$, mean $\left(T_{\text {mean }}\right)$, and minimum $\left(T_{\min }\right)$ temperature, mean relative humidity (RH), wind speed (WS), sunshine duration (SD), air pressure (PRESS) and daily amount of precipitation (PRCP) were collected from the China Meteorological Sharing Service System Network (http://cdc.cma.gov.cn/home.do) during the same period as the TB cases data.

Daily mean hourly air pollutants data (inhalable $\mathrm{PM}_{2.5}$ and $\mathrm{CO}$ ) were obtained from the Jinan Environmental Monitoring Center. The data was obtained from 14 fixed monitoring stations, spanning the entire region, including 11 sites located in urban areas and 3 sites located in suburban county areas. 
Daily average values of air pollution were used in this study and calculated the average from above 14 fixed monitoring stations.

\subsection{Statistical analysis}

Firstly, a descriptive analysis was performed to describe the distribution of TB cases, meteorological factors and pollutants during the study period. The minimum, maximum, quartiles, mean and standard deviation were calculated. The associations of TB cases with meteorological factors and air pollutants were assessed by Pearson's correlation test. Factors related to the incidence of TB were included in the model.

Secondly, the effect of $T_{\text {mean }}$ on TB cases was estimated utilizing a distributed lag non-linear model (DLNM) with quasi-Poisson regression. DLNM, a flexible modelling framework, describes simultaneously the shape of the relationship along both the space of the predictor and the lag dimension of its occurrence. [31]. As potential confounders, long-term trend/seasonality (by using day of study), day of the week (DOW), public holiday (HOD), RH, WS, SD, CO and $\mathrm{PM}_{2.5}$ were considered. Their effects were removed on by using smooth functions to calculate net effect of $T_{\text {mean }}$ on incidence of TB. [32] The degrees of freedom (df) of splines in different functions were automatically selected by Generalized Approximate Cross-Validation (GACV). The Pearson's correlation test and collinearity diagnosis were used to analyze the correlation and collinearity between the various factors. Generally, when $\left|r_{s}\right| \otimes 0.8$, it is considered that there is a strong correlation between factors; when the variance inflation factor (VIF) $\geq$ 10 , it is considered that there may be a serious collinearity between factors [33,34].

Instead of using a linear term, a cross matrix for the daily temperature was established to represent the non-linear and delayed effect. We selected a natural cubic spline basis to model the non-linear effects using three $\mathrm{df}$ in the temperature space, and the polynomials with four degrees to examine the delayed effect. Model selection for lag structure was carried out by minimizing the GACV criteria; these lag structure $(3,4,5,6,7,8,9,10,11,12$ weeks) corresponded to different GACV values $(1.680,1.677,1.680$, $1.667,1.666,1.673,1.665,1.655,1.661,1.661)$ during the modeling attempt. Referring to the previous study $[14,35]$ and GACV values, we set a maximum lag structure as 70 days (10 weeks) as it also is longer than the incubation period (4-8weeks). We used a temperature of $15.0^{\circ} \mathrm{C}$ (which was mean value of the $T_{\text {mean }}$ in Jinan, 2012 to 2015) as the reference value to calculate the relative risks (RRs), and used the minimum, the 5th and 25th of percentiles temperature as the cold temperature effect and the maximum, the 95th and 75th of percentiles temperature as the hot temperature effect.

Thirdly, a weather-stratified DLNM was developed to quantify the effect modification by other meteorological factors (RH, WS and SD). We used this model to estimate the temperature effect for two meteorological factors strata: <50th percentile and > 50th percentile. Meanwhile, in the research process, it was found that the effects of temperature ranging from the 25th to 75th quantile were basically not significant. We selected a double threshold function as basis to model the cold and hot temperature effects with the 25th and 75th quartiles as the cut-off points. We used the interval as a reference to estimate the cold temperature effect (the 5th percentile) and hot temperature effect (the 95th percentiles) 
by the RR with $95 \% \mathrm{Cl}$. Further, we also insert an interaction function of $\mathrm{T}_{\text {mean }}$ with $\mathrm{RH}, \mathrm{WS}$ or SD to identify whether the exists of effect modifications are due to chance. [36]

\subsection{Sensitivity analyses}

To check the robustness and validity of the main findings of this study, sensitivity analyses were performed by adjusting $d f$ of temperature $(d f=2,4,5)$, fitting the models to TB cases at lag 0 and lag $0-70$ days. Further, we also conducted sensitivity analyses by adjusting one environmental factor at a time or excluding all air pollution factors $\left(\mathrm{PM}_{2.5}, \mathrm{CO}\right)$ or all meteorological factors $(\mathrm{RH}, \mathrm{WS}, \mathrm{SD})$ from the model.

In this study, the relative risk (RR) and $95 \%$ confidence interval $(95 \% \mathrm{Cl})$ were used as the evaluation indexes of the effect. The analysis was performed by Stata software (version 15.0) and packages (splines, DLNM, mgcv) of R statistical software (version 3.5.2). Statistical significance was set at $\mathrm{P}<$ 0.05 .

\section{Results}

\subsection{Descriptive analysis}

During the study period January 1, 2012 to December $31,2015,15,010$ cases of TB were notified in the study area, and average $\mathrm{T}_{\max }$ was $19.9^{\circ} \mathrm{C}, \mathrm{T}_{\text {mean }} 15.0^{\circ} \mathrm{C}, \mathrm{T}_{\min } 10.8^{\circ} \mathrm{C}$ in Jinan. The 5 th, 25th, 75 th and 95th percentiles of daily $\mathrm{T}_{\text {mean }}$ were $-1.8^{\circ} \mathrm{C}, 5.2^{\circ} \mathrm{C}, 24.0^{\circ} \mathrm{C}$ and $29.0^{\circ} \mathrm{C}$. Table 1 presents descriptive statistics for TB cases, pollutants and meteorological factors in Jinan, respectively. The mean concentrations of $\mathrm{PM}_{2.5}$ and $\mathrm{CO}$ were $97 \mu \mathrm{g} / \mathrm{m}^{3}$ and $1408 \mu \mathrm{g} / \mathrm{m}^{3}$. The time-series distributions of TB cases and meteorological factors were shown in Fig. 1, demonstrating a seasonal trend for the series. The minimum of $T_{\text {mean }}$ gradually increased from 2012 to 2015, and the cases of TB fluctuated slightly with more cases occurring in spring and fall. 
Table 1

Summary of daily environmental variables and incidence of TB in Jinan city, 2012-2015

\begin{tabular}{|c|c|c|c|c|c|c|}
\hline \multirow[t]{2}{*}{ Variables } & \multirow[t]{2}{*}{ Minimum } & \multicolumn{3}{|c|}{ Percentile } & \multicolumn{2}{|c|}{ Maximum } \\
\hline & & 25th & 50th & 75th & & \\
\hline \multicolumn{7}{|l|}{ Pollutants $\left(\mu \mathrm{g} / \mathrm{m}^{3}\right)$} \\
\hline $\mathrm{PM}_{2.5}$ & 15 & 59 & 83 & 118 & 443 & $97 \pm 58$ \\
\hline $\mathrm{CO}$ & 465 & 990 & 1238 & 1631 & 6555 & $1408 \pm 654$ \\
\hline \multicolumn{7}{|c|}{ Meteorological Factor } \\
\hline Daily $\mathrm{T}_{\text {mean }}\left({ }^{\circ} \mathrm{C}\right)$ & -9.4 & 5.2 & 16.9 & 24.0 & 33.8 & $15.0 \pm 10.5$ \\
\hline Daily $\mathrm{T}_{\max }\left({ }^{\circ} \mathrm{C}\right)$ & -5.4 & 9.7 & 22.3 & 29.4 & 39.9 & $19.9 \pm 10.9$ \\
\hline Daily $\mathrm{T}_{\text {mix }}\left({ }^{\circ} \mathrm{C}\right)$ & -12.9 & 1.3 & 12.2 & 20.0 & 30.8 & $10.8 \pm 10.3$ \\
\hline Daily RH (\%) & 14 & 41 & 55 & 70 & 100 & $56 \pm 20$ \\
\hline Daily SD (h) & 0.00 & 3.20 & 7.00 & 9.00 & 13.30 & $6.15 \pm 3.73$ \\
\hline Daily WS (m/s) & 0.2 & 1.8 & 2.3 & 3.0 & 8.4 & $2.5 \pm 1.1$ \\
\hline Daily PRESS (hPa) & 975.7 & 988.7 & 996.7 & 1003.6 & 1021.8 & $996.5 \pm 9.1$ \\
\hline Daily PRCP (mm) & 0.00 & 0.00 & 0.00 & 0.00 & 600.00 & $4.43 \pm 26.90$ \\
\hline \multicolumn{7}{|l|}{ Case } \\
\hline TB & 0 & 2 & 4 & 7 & 26 & $5 \pm 4$ \\
\hline
\end{tabular}

$\mathrm{PM}_{2.5}$ fine particulate matter with an aerodynamic diameter of $<2.5 \mu \mathrm{m}$, CO carbon monoxide, $\mathrm{T}_{\text {mean }}$ daily average temperature, $T_{\max }$ daily maximum temperature, $T_{\min }$ daily minimum temperature, $R H$ relative humidity, SD sunshine duration, WS wind speed, PRESS pressure, PRCP daily amount of precipitation, TB case of TB

\subsection{Correlation analysis and collinearity diagnosis between TB cases and environmental factors}

Table.S1 exhibits the matrix of Pearson correlations between TB cases and other variables. TB was positive correlated with $T_{\text {mean }}, T_{\text {max }}, T_{\text {min }}$, SD and WS, and negative correlated with $\mathrm{PM}_{2.5}, C O, P R E S S$ and $\mathrm{RH}(\mathrm{P} \otimes 0.05)$. No statistical association was found between the TB cases and PRCP (P凶0.05). However, there was a strong negative correlation between PRESS and $T_{\text {mean }}\left(r_{s}=-0.87\right)$, and hence collinearity might exist. Variable PRCP unrelated to the number of cases and variable PRESS strongly related to 
$\mathrm{T}_{\text {mean }}$ were excluded from the model, and other meteorological factors were included in. Through collinearity diagnosis, it was found that the VIF values of all factors in the model were $₫ 5$, so there was no severe collinearity, and the model was established.

\subsection{The relationships between $\mathrm{T}_{\text {mean }}$ and number of TB cases}

Figure 2 illustrates the three-dimensional graph of a nonlinear relationship between $T_{\text {mean }}$ and TB cases, with reference at $15.0^{\circ} \mathrm{C}$. An immediate effect of the minimum temperature was observed on the current day $(\operatorname{lag} 0)$, with lower risk in the following days. Figure 3 presents the lag-response relationships between

different $T_{\text {mean }}$ levels (minimum, the 5th, 25th, 75th and 95th percentiles and maximum temperature) and incidence. The effect of the minimum temperature $\left(-9.4{ }^{\circ} \mathrm{C}\right)$ led to the risk in TB incidence at lag 0 and the second incidence peak at the lag 57 . It also showed the decrease trend of the risk and the lowest effect occurred at lag $23(\mathrm{RR}=0.95,95 \% \mathrm{Cl}: 0.93,0.97)$. The effect of the 5 th percentile of $\mathrm{T}_{\text {mean }}\left(-1.8^{\circ} \mathrm{C}\right)$ also presented a similar trend. The effect of the 25 th percentile of $\mathrm{T}_{\text {mean }}\left(5.2^{\circ} \mathrm{C}\right)$ remained insignificant and the risk of the 75 th percentile $\left(24.0^{\circ} \mathrm{C}\right)$ fluctuated slightly. Meanwhile, the 95 th percentile $\left(29.0^{\circ} \mathrm{C}\right)$ peaked after lag 14 and had no significance in the following days. For maximum $\mathrm{T}_{\text {mean }}\left(33.8^{\circ} \mathrm{C}\right)$, we found a consistent increase risk until the incidence peak at lag 16.

The lag effect and cumulative effect of temperature on TB incidence after different lag days when controlling for long-term trends, HOD, DOW, and meteorological factors and air pollution are shown in Fig. 4. Low temperature increased the relative risk of TB incidence at the lag 0 . The overall cumulative effect showed a U-shape; however, effects had considerable statistical variability reflected by large confidence intervals due to a small number of maximum and minimum $T_{\text {mean }}$ days. More specifically, relative to $15.0^{\circ} \mathrm{C}$, the colder temperature showed a lower risk after lag 21 and lag $0-42$ days. After lag 63 , the risk of TB incidence increased with the decrease of $\mathrm{T}_{\text {mean }}$, and the cumulative risk of $10.1^{\circ} \mathrm{C}$ was 0.90 (95\% Cl: $0.81,1.00)$ and of $25.2^{\circ} \mathrm{C}$ was 1.18 (95\% Cl: $\left.1.02,1.37\right)$ after lag $0-63$ days.

\subsection{The effect modification by meteorological factors}

Combined the effects at the cold temperature (the 5 th percentile of $\mathrm{T}_{\text {mean }}:-1.8^{\circ} \mathrm{C}$ ) compared with the 25th percentile $\left(5.2^{\circ} \mathrm{C}\right)$ and the hot temperature (the 95 th percentile of $\mathrm{T}_{\text {mean }}: 29.0^{\circ} \mathrm{C}$ ) compared with the 75th percentile $\left(24.0^{\circ} \mathrm{C}\right)$, are presented in Fig. 5. High RH increased the risk of TB in hot temperature situation after lag 21 and in cold temperature situation after lag 70, respectively; meanwhile, low $\mathrm{RH}$ decreased the risk of TB in cold temperature situation after lag 21 and in hot temperature situation after lag 70. In addition, low WS increased the risk for different temperature at different lag period; and high WS decreased the risk in hot temperature at lag 49. Furthermore, low SD increased the risk in cold temperature situation at lag 21. By verifying the interaction terms, the interactions of $R H(P=0.001)$, WS $(P=0.004)$ and $S D(P=0.02)$ with $T_{\text {mean }}$ were significant, respectively.

\subsection{Sensitivity analyses}


Table.S2 contains details of the results from the sensitivity analyses. When we changed $\mathrm{df}(2,4,5 \mathrm{df})$ for the temperature space in the DLNM, the estimated changes were slightly smaller. Adjusting for meteorological factors slightly changed the overall cumulative RRs, whereas adjusting for air pollution gave slightly larger in cold effect but still did not change substantially. Our sensitivity analyses suggested that the results were not dependent on modeling assumptions.

\section{Discussion}

We examined the effects of ambient temperature on TB cases in Jinan, one of the so-called four "ovens" with serious air pollution in mid-eastern China, during the period of 2012 to 2015 . Study findings indicated that the temperature-incidence relationship was non-linear, with showing an S-shape at the current day and a $U$ curve over lag 0-70 days. Further, the minimum $T_{\text {mean }}$ effect appeared immediately with a following harvest effect, and the second onset peak appeared after lag 8-9 weeks, whereas the maximum $T_{\text {mean }}$ effect became predominant with about two weeks' lag. Meanwhile, the $T_{\text {mean }}$ effect on incidence of TB modified by different levels of RH, WS and SD, and varied across different lag period.

Our results of a negative and non-linear relationship between ambient temperature and notified cases of TB infection are consistent with research carried out in other countries with different weather conditions $[14,17,35]$. We also found that the risk of TB incidence was greatly affected by extreme temperature on the current day. On the other hand, the overall cumulative effect showed trends for increased risks for decline of cold temperature and increase of hot temperature.

Many investigators $[14,17,37]$ have reported the delayed effect in the relationship between TB and cold or hot effect. Our study also confirmed that the delayed effect existed. For the effects of the minimum and the 5th percentile of $\mathrm{T}_{\text {mean }}$, the immediate effects appeared at that day, and the second onset peak appeared at lag 8-9 weeks. For the effects of the 75th, 95th percentiles and maximum of $T_{\text {mean }}$, the onset peak appeared after lag about two weeks. The peak of cold effect appeared earlier than that of hot effect, which is comparable to the results of a study [14] conducted in Japan. In contrast to this study's findings, however, the results in the Japan study showed that high temperature effects were generally constant at lag periods of up to 12 weeks, whereas the effects in low temperature ranges were persistent over shorter lag periods and diminished over time. This may be due to the warm climate in Japan, so the 5 th percentile temperature $\left(5.4^{\circ} \mathrm{C}\right)$ in the Japan study was only equivalent to the 25 th percentile in our study. Yuanyuan Xiao[35] found that average temperature was inversely associated with TB incidence at a lag period of 2 months. Similarly, we found that $T_{\text {mean }}$ under $15^{\circ} \mathrm{C}$ was also negatively associated with TB at lag 63, but hot effect was not significant.

The difference in lag effects as our results of DLNMs suggested would be also related to some characteristics, and some researchers have provided this context for interpreting our results. Fares [38] manifested that lower temperature during winter may induce the susceptibility to respiratory epithelium infection. The fluctuation in weather temperature during winter may also act on the respiratory epithelium by slowing mucociliary clearance and inhibiting phagocytosis, causing pathophysiological responses, 
which then lead to increase the susceptibility to infection. [39] In addition, in winter in Jinan, the citywide coal-burning heating exacerbates smog, which would increase the number of carriers that can spread pathogens [20] and increase the risk of RD; Liu [23] provided the evidence that heavy pollution are positively correlated with TB incidence. Furthermore, Naranbat [13] hypothesized that temperature may change the time people spend at home or outside. China is a populous country, people gather, and close door and windows during the cold winter, and the crowded indoor environment is also a risk factor for infectious diseases. As the temperature gradually increases with an agreeable weather, citizens were more willing to play outside and open the window for ventilation. Meanwhile, the heat of the summer might trigger a thermal reaction, but it also comes with a reluctance to congregate for residents, preferring to stay indoors with air conditioning. Which may not induce the high risk of transmission of tuberculosis as cold temperature do.

We found some evidence of harvesting effect in our study; there was an incidence deficit for the minimum and the 5th percentile $T_{\text {mean }}$ at the lag about 3 weeks. We speculate that the harvesting effect would support the mechanism of temperature influencing the incidence risk. In particular, it may be that presents in extreme cold temperature only hasten the TB incidences of individuals in a small, frail, infected subset of the population who will attack even in the absence of extreme cold effect. A possible reason is extreme cold air attacks the body's respiratory and immune systems, speeding up the onset of TB to infected people. In contrast, hot temperature might mainly disturb the body's cardiovascular system, and has little direct effect on the respiratory system. [40]

However, meteorological factors may play an important role. Our findings showed that low RH decreased the risk of TB for temperature which was different from Yingjie Zhang's research[41]. In cold temperature situation, the increased $\mathrm{RH}$ may create a suitable environment for the growth and reproduction of tuberculosis. Our study also suggested that low WS could increase the effect of low $T_{\text {mean }}$ on TB at the current day and at lag 70. The higher WS could accelerate ventilation, dilute the concentration of bacteria and help reduce the risk of becoming infected. Although another study [18] indicated that areas with stronger wind speeds tend to have a higher infection risk, our study findings were supported by the findings of Kai Cao[42]. As has been found in a few other studies [17, 42, 43], the low SD would raise the risk of TB. Our findings showed that the low level of SD positively modified on cold temperature effect. We speculate that this result would be also related to some view point indicated by these studies $[44,45]$ on TB that low serum vitamin D levels were associated with higher risk of active tuberculosis. The low SD would affect the absorption of vitamin D for public. However, there was still a lack of validation of biological mechanisms of vitamin D on TB, which should be a further direction.

A study limitation is the use of data on temperature and air pollution from fixed monitoring sites rather than measuring individual exposure, which would bring about measurement errors because individual exposure temperature may be not entirely identify with outdoor average temperature. Secondly, cold effect and hot effect was calculated by comparing the 5th to the 25th percentile and the 95th to the 75th percentile temperatures. This accounted for the effect of cold and hot temperature to some extent. But the reason for this way is that the study population is not sensitive to $T_{\text {mean }}$ ranging from the 25 th to the 
75th percentile, there may be inappropriateness when extrapolating calculating method to an unequal population or other diseases. Because the complexity of other factors and the difference of population adaptation. In addition, we only used data from Jinan to examine the effects of temperature on incidence of TB so the findings may not be generalizable to other areas.

In conclusion, tuberculosis incidence in Jinan was found to be nonlinear and negative related with temperature, with a harvesting effect for cold temperature. Findings of this study add to the evidence that high temperatures have slower delayed effects on TB incidence while low temperatures appear to exhibit higher effects. Temperature may determine the amount of time spent indoors and affect the ability of bacteria to survive, and thus the transmissibility of Mycobacterium tuberculosis. Results also suggest that considering effect modification by RH, WS and SD in assessing temperature effects on TB incidence may be essential. These findings may have important implications for public health officials to control and prevent the TB risk of exposure to ambient temperature. Meanwhile, the public are also suggested to keep clear life environment, ventilate usually and supplement Vitamin D. Although China has achieved the 2015 global TB control goal, still a million incident TB cases are reported annually. [10] Exploring the influencing factor and mechanism of TB can shed light on future TB control programs in China and even other country.

\section{Declarations}

Ethics approval and consent to participate

Not applicable

Consent for publication

Not applicable

Availability of data and materials

The datasets generated and/or analyzed during the current study are not publicly available.

Competing interests

The authors declare that they have no competing interests

Funding

Medicine and Technology Development Plan Project of Shandong Province (2015WS0435);

National Science Foundation of China (Grant Number: 71473152);

Key Research \& Development Program of Shandong Province (2016GSF202035, 2017GSF218052 and GG201703220225). 
RY process the conceptualization and formal analysis by software and writing of original draft; LC process the investigation and collect the data, funding acquisition and supervision for study; RY and LC contributed equally to this work and should be considered as co-first authors; JZ and MW process the investigation for this research and funding Acquisition; CJ process the conceptualization and methodology for the research design and formal analysis; SR process the visualization and funding acquisition for this study; $\mathrm{CJ}$ and SR contributed equally should be considered as co-corresponding authors. All authors read and approved the final manuscript.

Acknowledgements

This work was funded by grants from the Medicine and Technology Development Plan Project of Shandong Province (2015WS0435), National Science Foundation of China (Grant Number: 71473152), Key Research \& Development Program of Shandong Province (2016GSF202035, 2017GSF218052 and GG201703220225).

\section{References}

1. Kunst AE, Looman CW, Mackenbach JP: Outdoor air temperature and mortality in The Netherlands: a time-series analysis. American Journal of Epidemiology 1993, 137(3):331-341. https://doi.org/10.1007/BF00938210

2. Shaposhnikov D, Revich B: Climate Change and Projections of Temperature-Related Mortality; 2018.

3. Yu SW: High ambient temperature and mortality: A review of epidemiologic studies from 2001 to 2008. Environmental Health 2009, 8(1):1-13. https://doi.org/10.1186/1476-069X-8-40

4. Li M, Zhou M, Yang J, Yin P, Wang B, Liu Q: Temperature, temperature extremes, and cause-specific respiratory mortality in China: a multi-city time series analysis. Air Quality Atmosphere \& Health 2019. https://doi.org/10.1007/s11869-019-00670-3.

5. Yang J, Zhou M, Ou CQ, Yin P, Li M, Tong S, Gasparrini A, Liu X, Li J, Cao L: Seasonal variations of temperature-related mortality burden from cardiovascular disease and myocardial infarction in China. Environmental Pollution 2017, 224:400. https://doi.org/10.1016/j.envpol.2017.02.020

6. Heaney A, Little $\mathrm{E}, \mathrm{Ng} \mathrm{S}$, Shaman J: Meteorological variability and infectious disease in Central Africa: a review of meteorological data quality. Annals of the New York Academy of Sciences 2016, 1382(1):31-43. https://doi.org/10.1111/nyas.13090.

7. Tian L, Liang F, Xu M, Jia L, Pan X, Clements ACA: Spatio-temporal analysis of the relationship between meteorological factors and hand-foot-mouth disease in Beijing, China. BMC infectious diseases 2018, 18(1):158. https://doi.org/10.1186/s12879-018-3071-3.

8. Chien LC, Lin RT, Liao Y, Sy FS, Perez A: Surveillance on the endemic of Zika virus infection by meteorological factors in Colombia: a population-based spatial and temporal study. BMC infectious diseases 2018, 18(1):180. https://doi.org/10.1186/s12879-018-3085-x. 
9. Wang H, Di B, Zhang T, Lu Y, Chen C, Wang D, Li T, Zhang Z, Yang Z: Association of meteorological factors with infectious diarrhea incidence in Guangzhou, southern China: A time-series study (20062017). The Science of the total environment 2019, 672:7-15. https://doi.org/10.1016/j.scitotenv.2019.03.330.

10. Global tuberculosis report 2018 [https://www.who.int/tb/publications/global_report/en/]

11. Douglas AS, Strachan DP, Maxwell JD: Seasonality of tuberculosis: the reverse of other respiratory diseases in the UK. Thorax 1996, 51(9):944-946. https://doi.org/10.1136/thx.51.9.944.

12. Willis MD, Winston CA, Heilig CM, Cain KP, Mac Kenzie WR, Walter ND: Seasonality of Tuberculosis in the United States, 1993-2008. Clinical Infectious Diseases 2012, 54(11):1553-1560. https://doi.org/10.1093/cid/cis235.

13. Naranbat N, Nymadawa P, Schopfer K, Rieder HL: Seasonality of tuberculosis in an Eastern-Asian country with an extreme continental climate. European Respiratory Journal 2009, 34(4):921-925. https://doi.org/10.1183/09031936.00035309.

14. Onozuka $D$, Hagihara $A$ : The association of extreme temperatures and the incidence of tuberculosis in Japan. International Journal of Biometeorology 2015, 59(8):1107-1114. https://doi.org/10.1007/s00484-014-0924-3

15. Beiranvand R, Karimi A, Delpisheh A, Sayehmiri K, Soleimani S, Ghalavandi S: Correlation assessment of climate and geographic distribution of tuberculosis using Geographical Information System (GIS). Iranian Journal of Public Health 2016, 45(1):86-93.

16. Koh GC, Hawthorne G, Turner AM, Kunst H, Dedicoat M: Tuberculosis incidence correlates with sunshine: an ecological 28-year time series study. PLoS One 2013, 8(3):e57752. https://doi.org/10.1371/journal.pone.0057752.

17. Rao H-X, Zhang X, Zhao L, Yu J, Ren W, Zhang X-L, Ma Y-C, Shi Y, Ma B-Z, Wang X et al: Spatial transmission and meteorological determinants of tuberculosis incidence in Qinghai Province, China: a spatial clustering panel analysis. Infectious diseases of poverty 2016, 5(1):45-45. https://doi.org/10.1186/s40249-016-0139-4.

18. Li Q, Liu M, Zhang Y, Wu S, Yang Y, Liu Y, Amsalu E, Tao L, Liu X, Zhang F et al: The spatio-temporal analysis of the incidence of tuberculosis and the associated factors in mainland China, 2009-2015. Infection, genetics and evolution : journal of molecular epidemiology and evolutionary genetics in infectious diseases 2019:103949. https://doi.org/10.1016/j.meegid.2019.103949.

19. Cole EC, Cook CE: Characterization of infectious aerosols in health care facilities: an aid to effective engineering controls and preventive strategies. American Journal of Infection Control 1998, 26(4):453-464.

20. Fernstrom A, Goldblatt M: Aerobiology and its role in the transmission of infectious diseases. Journal of pathogens 2013, 2013:493960. https://doi.org/10.1155/2013/493960.

21. Smith GS, Van Den Eeden SK, Garcia C, Shan J, Baxter R, Herring AH, Richardson DB, Van Rie A, Emch M, Gammon MD: Air Pollution and Pulmonary Tuberculosis: A Nested Case-Control Study 
among Members of a Northern California Health Plan. Environ Health Perspect 2016, 124(6):761768. https://doi.org/10.1289/ehp.1408166.

22. Fernandes FMC, Martins ES, Pedrosa D, Evangelista M: Relationship between climatic factors and air quality with tuberculosis in the Federal District, Brazil, 2003-2012. The Brazilian journal of infectious diseases : an official publication of the Brazilian Society of Infectious Diseases 2017, 21(4):369-375. https://doi.org/10.1016/j.bjid.2017.03.017.

23. Liu Y, Cui L, Hou L, Yu C, Tao N, Liu J, Li Y, Zhou C, Yang G, Li H: Ambient Air Pollution Exposures and Newly Diagnosed Pulmonary Tuberculosis in Jinan, China: A Time Series Study. Scientific reports 2018, 8(1):17411. https://doi.org/10.1038/s41598-018-35411-6.

24. Kim J: Is ambient air pollution another risk factor of tuberculosis? Korean J Intern Med 2014, 29(2):170-172. https://doi.org/10.3904/kjim.2014.29.2.170.

25. Basu R, Samet JM: Relation between elevated ambient temperature and mortality: A review of the epidemiologic evidence. Epidemiologic Reviews 2002, 24(2):190-202.

https://doi.org/10.1093/epirev/mxf007.

26. Basu R: High ambient temperature and mortality: a review of epidemiologic studies from 2001 to 2008. Environmental Health 2009, 8(1):40. https://doi.org/10.1186/1476-069x-8-40.

27. Jinan Statistical Bureau: Jinan Statistical Yearbook: China Statistics Press; 2018.

28. Wang JX, Rui LI, Yi SU, Bureau JM: Winter temperature characteristics of Jinan during 1951-2015. China Population Resources Environment 2016.

29. Eight major weather and climate events in Jinan in 2017 [http://sd.cma.gov.cn/gslb/jnsqxj/xwzx/gzdt/201801/t20180102_17583.html]

30. Top ten weather and climate events in Jinan in 2016 [http://sd.cma.gov.cn/gslb/jnsqxj/xwzx/gzdt/201701/t20170104_17026.html]

31. Gasparrini A, Armstrong B, Kenward MG: Distributed lag non-linear models. Statistics in Medicine 2011, 29. https://doi.org/10.1002/sim.3940.

32. Hastie T, Tibshirani R: Generalized Additive Models. Statistical Science 1990, 1(3):297-310. https://doi.org/10.1214/ss/1177013604

33. D. Beaumont C, Belsley D, Kuh E, E. Welsch R: Regression Diagnostics - Identifying Influential Data and Sources of Collinearity, vol. 32; 1981.

34. Schroeder MA, Lander J, Levine-Silverman S: Diagnosing and Dealing with Multicollinearity. Western Journal of Nursing Research 1990, 12(2):175-187. https://doi.org/10.1177/019394599001200204.

35. Xiao Y, He L, Chen Y, Wang Q, Meng Q, Chang W, Xiong L, Yu Z: The influence of meteorological factors on tuberculosis incidence in Southwest China from 2006 to 2015. Scientific reports 2018, 8(1):10053-10053. https://doi.org/10.1038/s41598-018-28426-6.

36. Kamangar F: Effect modification in epidemiology and medicine. Archives of Iranian medicine 2012, 15(9):575-582. https://doi.org/012159/aim.0014. 
37. Liao C-M, Hsieh N-H, Huang T-L, Cheng Y-H, Lin Y-J, Chio C-P, Chen S-C, Ling M-P: Assessing trends and predictors of tuberculosis in Taiwan. BMC public health 2012, 12:29-29. https://doi.org/10.1186/1471-2458-12-29.

38. Fares A: Seasonality of tuberculosis. Journal of global infectious diseases 2011, 3(1):46-55. https://doi.org/10.4103/0974-777X.77296.

39. Mourtzoukou EG, Falagas ME: Exposure to cold and respiratory tract infections. The international journal of tuberculosis and lung disease : the official journal of the International Union against Tuberculosis and Lung Disease 2007, 11(9):938-943. https://doi.org/10.1093/bmb/61.1.45

40. Roberts S, Switzer P: Mortality displacement and distributed lag models. Inhalation toxicology 2004, 16(14):879-888. https://doi.org/10.1080/08958370490519598.

41. Zhang Y, Liu M, Wu SS, Jiang H, Zhang J, Wang S, Ma W, Li Q, Ma Y, Liu Y et al: Spatial distribution of tuberculosis and its association with meteorological factors in mainland China. BMC infectious diseases 2019, 19(1):379. https://doi.org/10.1186/s12879-019-4008-1.

42. Cao K, Yang K, Wang C, Guo J, Tao L, Liu Q, Gehendra M, Zhang Y, Guo X: Spatial-Temporal Epidemiology of Tuberculosis in Mainland China: An Analysis Based on Bayesian Theory. International journal of environmental research and public health 2016, 13(5):469. https://doi.org/10.3390/ijerph13050469.

43. Koh GCKW, Hawthorne G, Turner AM, Kunst H, Dedicoat M: Tuberculosis incidence correlates with sunshine: an ecological 28-year time series study. PloS one 2013, 8(3):e57752-e57752. https://doi.org/10.1371/journal.pone.0057752.

44. Wilkinson RJ, Llewelyn M, Toossi Z, Patel P, Pasvol G, Lalvani A, Wright D, Latif M, Davidson RN: Influence of vitamin $D$ deficiency and vitamin $D$ receptor polymorphisms on tuberculosis among Gujarati Asians in west London: a case-control study. The Lancet 2000, 355(9204):618-621. https://doi.org/https://doi.org/10.1016/S0140-6736(99)02301-6.

45. Nnoaham KE, Clarke A: Low serum vitamin D levels and tuberculosis: a systematic review and metaanalysis. International journal of epidemiology 2008, 37(1):113-119. https://doi.org/10.1093/ije/dym247.

\section{Supplementary Files Legend}

Table. A.1 Pearson correlations between meteorological factors, air pollutants and incidence of TB in Jinan city, 2012-2015

Table. A.2 Sensitivity analyses of estimating association of temperature with TB incidence at lag 0 and over lag 0-70 days by changing degrees of freedom (df) and confounders in modeling assumptions

\section{Figures}



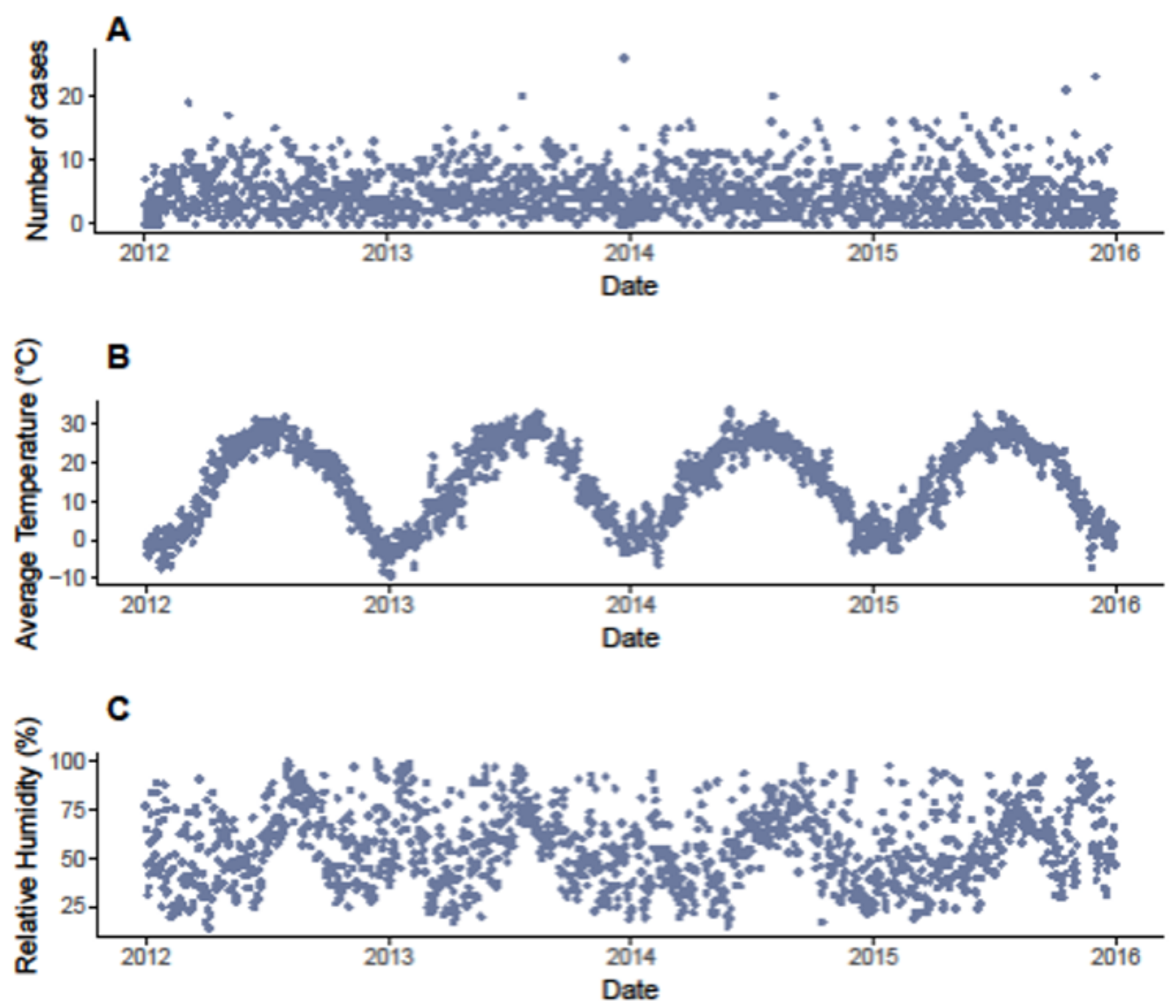

D
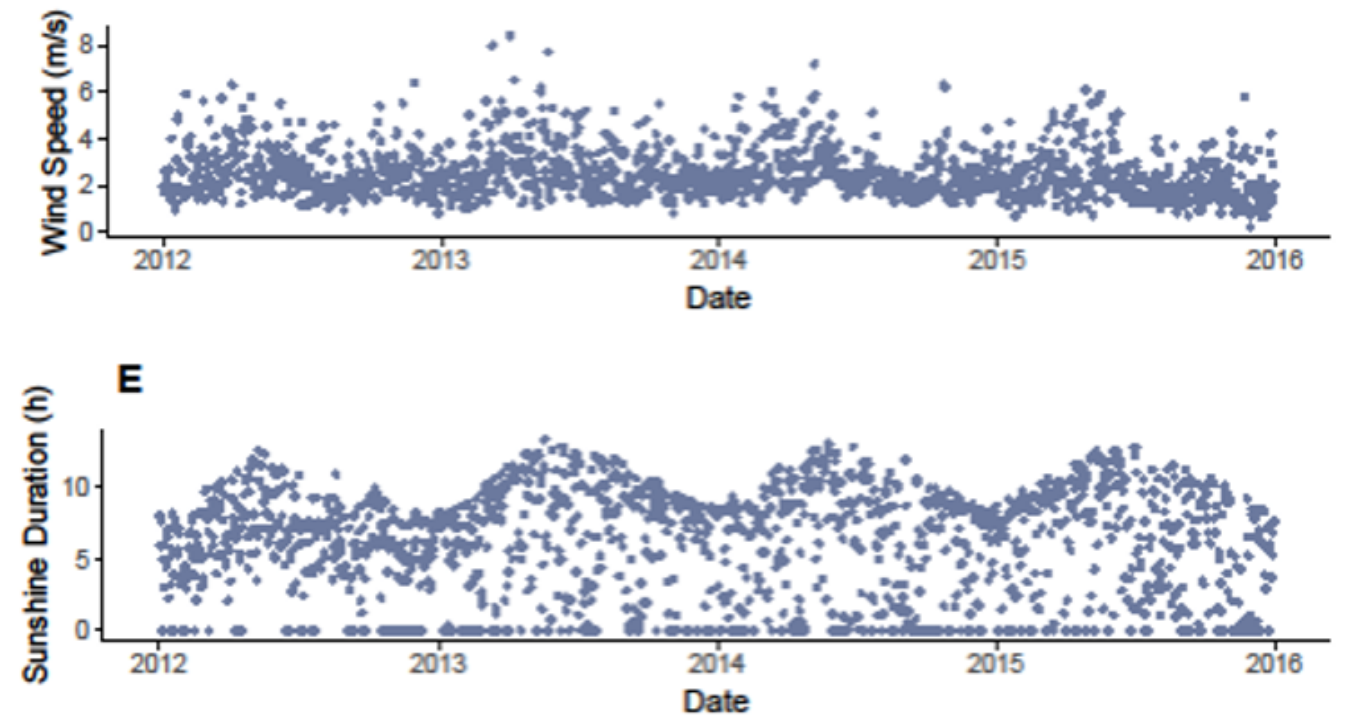

Figure 2

Daily time series of number of tuberculosis cases and meteorological factors for the period from 2012 to 2015 in Jinan 


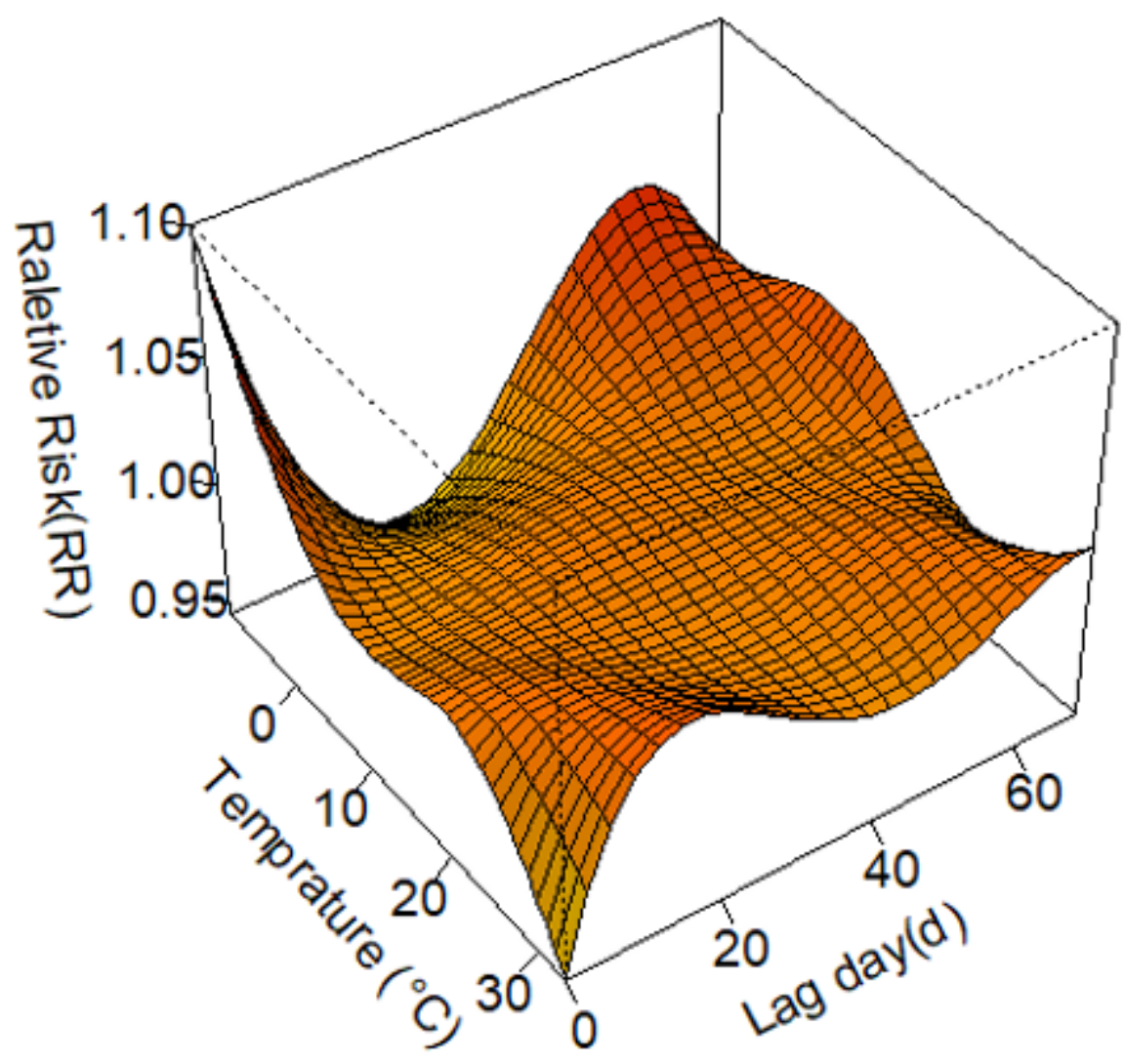

\section{Figure 3}

Relative risk of incidence of tuberculosis by daily average temperature $\left({ }^{\circ} \mathrm{C}\right)$ and days of lag, with reference value at mean temperature $\left(15.0^{\circ} \mathrm{C}\right)$, adjusting for $\mathrm{PM} 2.5, \mathrm{CO}$, relative humidity, wind speed, sunshine duration, public holiday, day of the week, and time trend
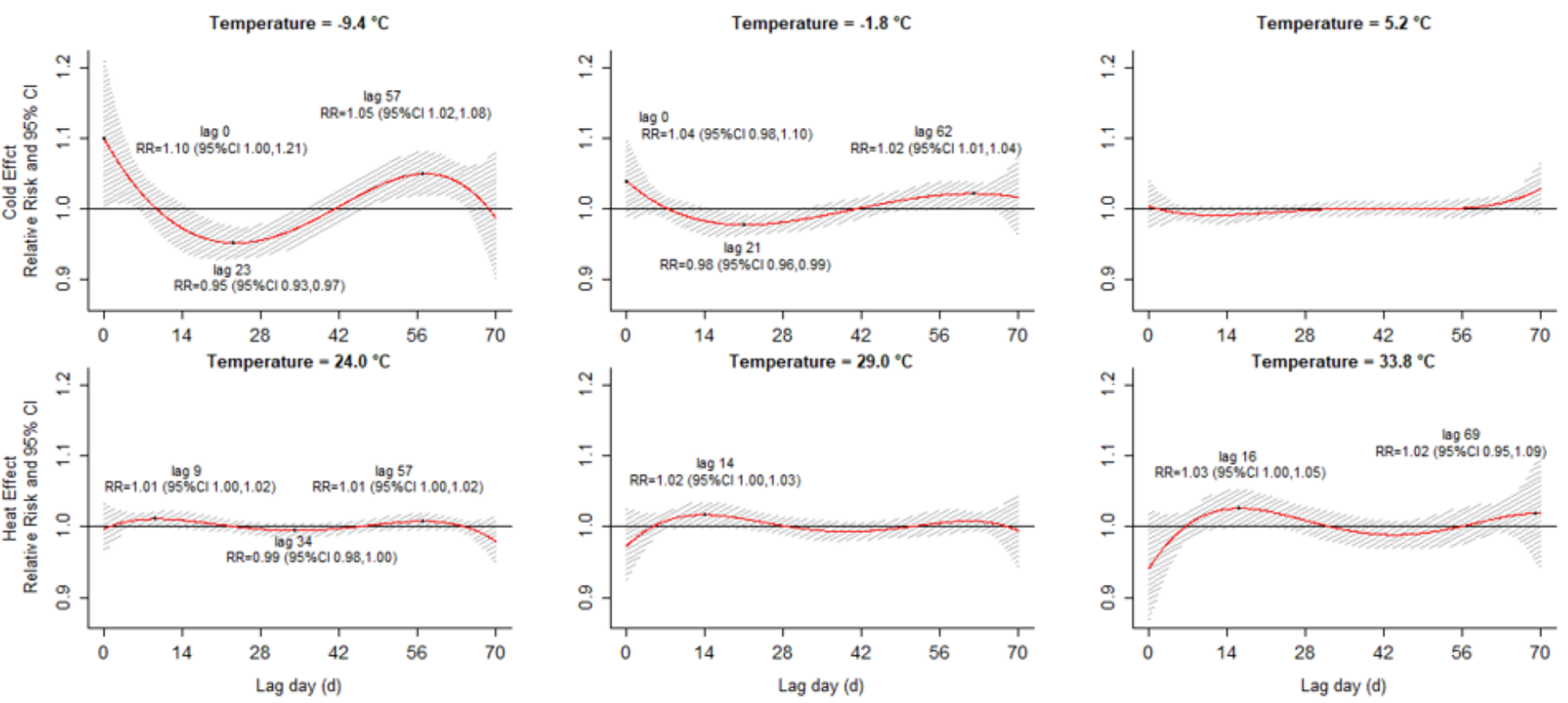


\section{Figure 5}

The effects of daily average temperature $\left({ }^{\circ} \mathrm{C}\right)$ on incidence of tuberculosis along days of lag, adjusting for PM2.5, CO, relative humidity, wind speed, sunshine duration, public holiday, day of the week, and time trend. The continuous curves are relative risks of incidence comparing the minimum, 5th, 25th, 75th, 95th and maximum percentile of temperatures with $95 \% \mathrm{Cl}$ (shaded area)
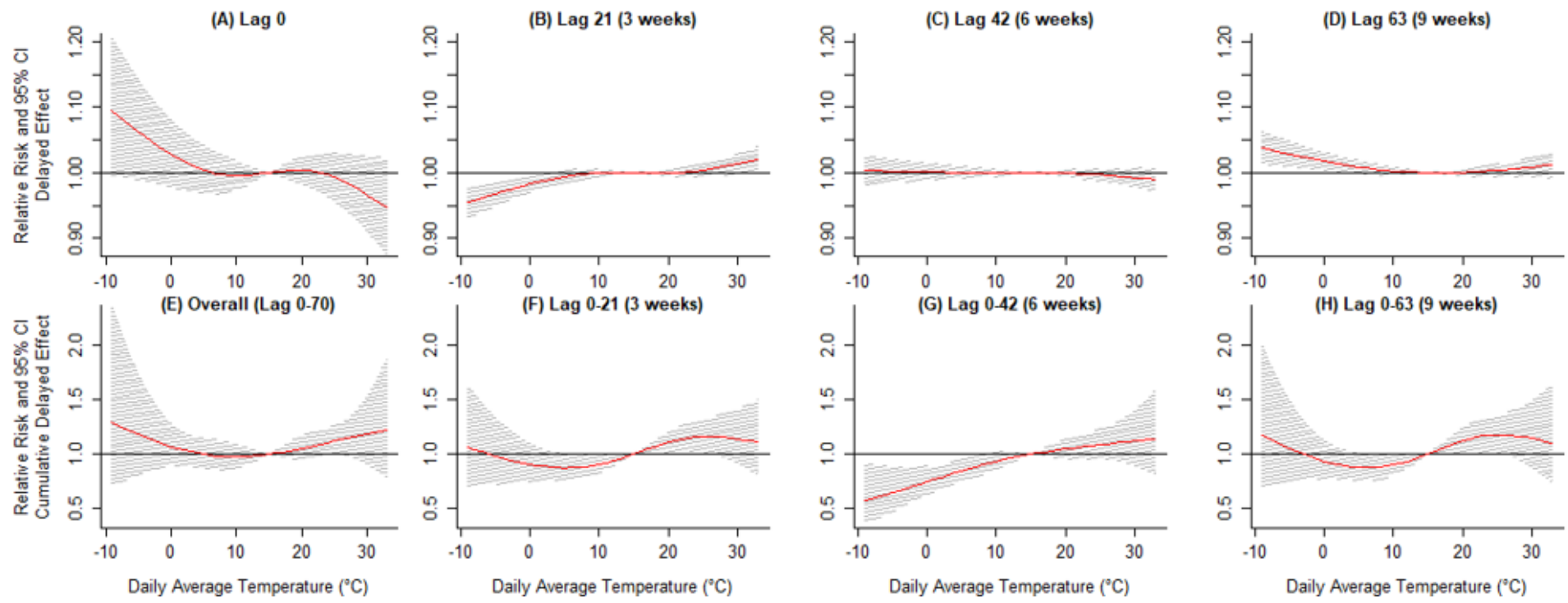

Figure 7

Pooled relative risks of TB incidence by daily average temperature over (A)lag 0 , (B) $\operatorname{lag} 21,(C) \operatorname{lag} 42$, (D)lag 63, (E)lag 0-70, (F)lag 0-21, (G)lag 0-42, (H)lag 0-63 days, adjusting for PM2.5, CO, relative humidity, wind speed, sunshine duration, public holiday, day of the week, and time trend. The continuous curves represent the RRs for incidence with reference at $15.0{ }^{\circ} \mathrm{C}$, with the $95 \% \mathrm{Cl}$ (shaded area) 

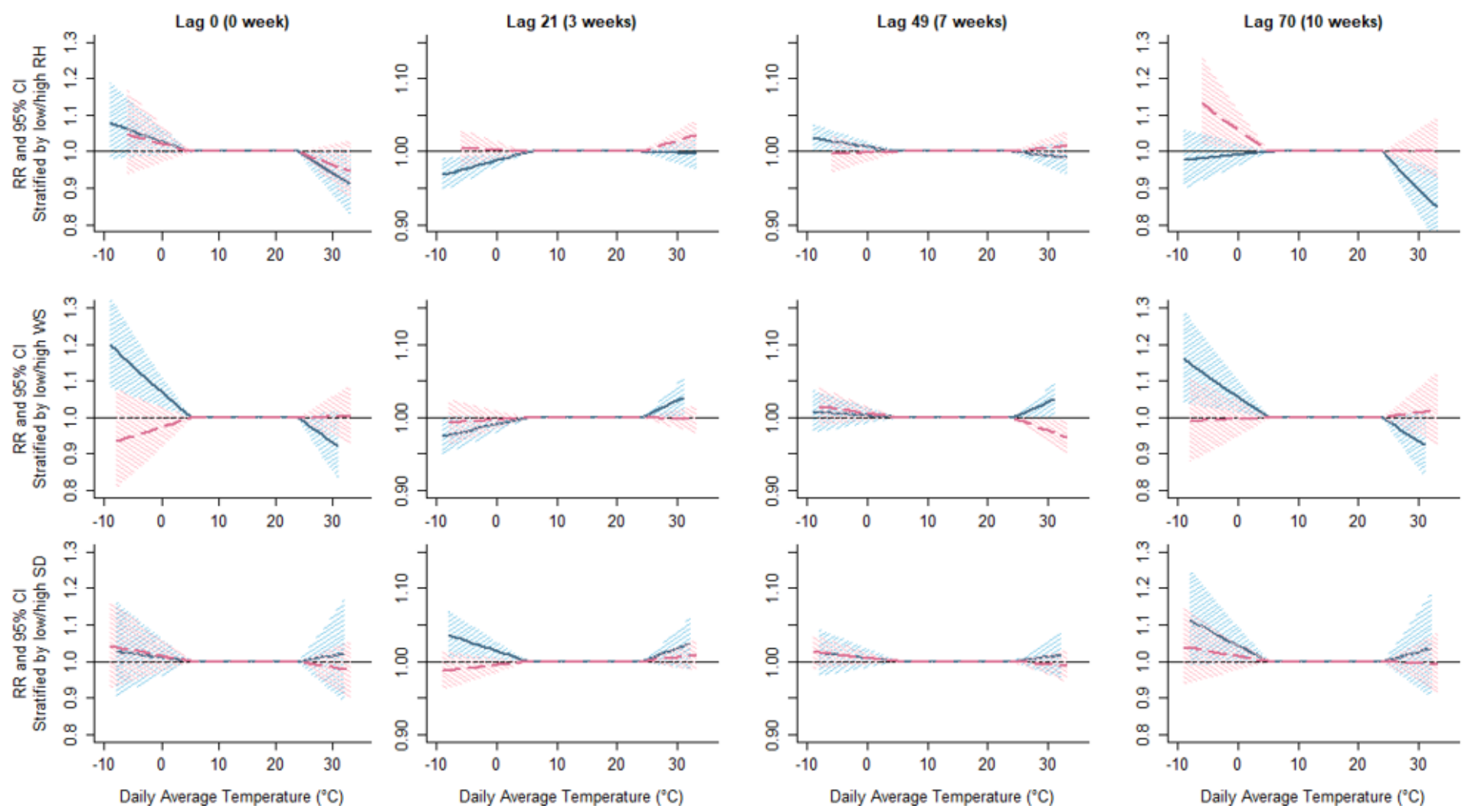

Figure 10

Effect modification of the association between daily average temperature $\left({ }^{\circ} \mathrm{C}\right)$ and tuberculosis by relative humidity (RH), wind speed (WS) and sunshine duration (SD) strata, adjusting for PM2.5, CO, public holiday, day of the week, time trend and other meteorological factors. The solid lines are the RRs of temperature for the low level strata, while the dotted lines are the RRs of temperature for the high level strata, with the $95 \% \mathrm{Cl}$ (shaded area)

\section{Supplementary Files}

This is a list of supplementary files associated with this preprint. Click to download.

- AppendixTables12.docx

- AppendixTables12.docx 